\title{
Challenges of defining a non-inferiority margin: a case study of non-inferiority randomized controlled trials of oral anti-thrombolytic agents for prophylaxis of venous thromboembolic events after orthopedic surgery
}

\author{
Grace Wangge ${ }^{1 *}$, Olaf H Klungel ${ }^{1}$, Kit CB Roes ${ }^{2}$, Antonius de Boer ${ }^{1}$, Arno W Hoes ${ }^{2}$, Mirjam J Knol ${ }^{1,2}$
}

From Clinical Trials Methodology Conference 2011

Bristol, UK. 4-5 October 2011

\section{Objective}

To identify problems and difficulties in determining a non-inferiority (NI) margin using the case of NI randomized controlled trials (RCTs) of oral anti-thrombolytic agents for prophylaxis of venous thromboembolic events (VTE) after orthopedic surgery.

\section{Methods}

We searched in Pubmed and Cochrane-central-registerfor-controlled-trials for all NI RCTs of direct thrombin inhibitors (DTI) and direct inhibitors of factor Xa (DXAI) for prophylaxis of VTE. All NI trials had enoxaparin as their active comparator. Using the draft FDA guidelines for NI trials, we determined an NI margin, referred to as the reference NI margin, based on all published placebo-controlled trials on enoxaparin for the same indication, identified in PubMed and Cochranecentral-register-for-controlled-trials. We used preservedeffects of $50 \%$ and $67 \%$ to calculate the reference NI margin.

\section{Results}

We identified 12 NI trials and 4 placebo-controlled trials of enoxaparin from our searches. All NI trials studied oral drugs. Trials in DTI used the risk difference (RD) to define their NI margin, and it ranged from 0.02 to 0.092 . Trials in DXAI used the RD

\footnotetext{
${ }^{1}$ Department of Pharmacoepidemiology \& Clinical Pharmacology, Utrecht Institute for Pharmaceutical Sciences (UIPS), University of Utrecht, The Netherlands

Full list of author information is available at the end of the article
}

(ranging from 0.035 to 0.056 ) or risk ratio (RR) (1.25) or both to define their NI margin. Furthermore, the NI margins using the RD were stricter than the $50 \%$ preserved-effects reference NI margin ((0.02 to 0.092) vs. $0.115)$. The NI margins in the trials using the RR were stricter than the 50 and $67 \%$ preserved-effects reference NI margin (1.25 vs. 1.46 and 1.28). In one trial, the test drug might have been concluded as non-inferior to enoxaparin if the $50 \%$ preserved-effects reference NI margin of RR were used.

\section{Conclusions}

Although a same comparator was used, a large variation in NI margins among NI RCTs of oral anti-thrombolytic agents for prophylaxis of VTE after orthopedic surgery exists. Using different NI margins could lead to different conclusions of the drug's efficacy. Challenges that became apparent during determination of an NI margin were 1) missing unpublished results of placebo-controlled trials, 2) how similar should placebo-controlled trials and NI trials be to maintain the constancy assumption, 3) whether fixed or random effects analysis should be used in the meta-analysis, 4) whether to calculate the NI margin on an absolute or relative scale, 5) which preserved-effects to use, and 6) whether further clinical judgment is needed.

\footnotetext{
Author details

${ }^{1}$ Department of Pharmacoepidemiology \& Clinical Pharmacology, Utrecht Institute for Pharmaceutical Sciences (UIPS), University of Utrecht,
} 
Published: 13 December 2011

doi:10.1186/1745-6215-12-S1-A32

Cite this article as: Wangge et al:: Challenges of defining a non-

inferiority margin: a case study of non-inferiority randomized controlled

trials of oral anti-thrombolytic agents for prophylaxis of venous

thromboembolic events after orthopedic surgery. Trials 2011 12(Suppl 1): A32.

Submit your next manuscript to BioMed Central and take full advantage of:

- Convenient online submission

- Thorough peer review

- No space constraints or color figure charges

- Immediate publication on acceptance

- Inclusion in PubMed, CAS, Scopus and Google Scholar

- Research which is freely available for redistribution

Submit your manuscript at 